\title{
Guía de buenas prácticas en Odontología para Uruguay durante la pandemia Covid-19.
}

Profa. Dra. María Renée Romero

Cátedra de Farmacología - Facultad de Odontología - UdelaR Orcid: 0000-0001-9616-1893

Rutas de propagación en la consulta El virus SARS-CoV-2 se ha detectado en secreciones respiratorias (tracto respiratorio superior e inferior) y heces. Se considera que la ruta principal de transmisión es a través de la inhalación de grandes gotas respiratorias o la deposición en las mucosas. Se ha detectado ARN viral en la sangre, pero no hay evidencia de que el SARS-CoV-2 pueda transmitirse a través del contacto con la sangre. Otra ruta implicada en la transmisión del virus SARS-CoV-2es el contacto con fómites contaminados debido a la persistencia del virus en las superficies y la vía fecal - oral. ${ }^{(1)}$

Evidencia de persistencia en el medio ambiente Recientes publicaciones han evaluado la supervivencia del SARS-CoV-2 en diferentes superficies. Para van Doremalen et al.2 la estabilidad ambiental del SARS-CoV-2 es de hasta tres horas en el aire, hasta cuatro horas en cobre, hasta 24 horas en cartón y hasta dos o tres días en plástico y acero inoxidable, aunque con títulos significativamente disminuidos. ${ }^{(1)}$

Se han detectado diferentes niveles de contaminación ambiental en habitaciones de pacientes con COVID-19, las partículas de virus pueden ser desplazadas por el aire y depositadas en las superficies. ${ }^{(1)}$

Fases de la Pandemia en relación a los procedimientos preventivos.

\section{FASE 1}

Empieza cuando se advierte la presencia del virus a los otros países con el fin de que se adopten algunas acciones ante la posible llegada de casos. De acuerdo con la OMS, durante este periodo, conociendo el avance del virus en otros países, deberán establecerse hospitales para la atención de casos futuros y se comienza a establecer un protocolo sanitario en los puntos de ingreso al territorio, como fronteras y aeropuertos. 


\section{FASE 2}

Es la fase de contención y comienza cuando se tiene identificadas a las personas que traen el virus desde el extranjero (casos importados). Se aplican protocolos de aislamiento. Las medidas de prevención de contagio se vuelven más enfáticas: distanciamiento social, lavado de manos.

\section{FASE 3}

Es la etapa de contagio comunitario. Aparecen casos locales de personas que no han estado en contacto directo con los casos importados, es decir, el virus ya está en la comunidad. ${ }^{(3-4)}$ En la etapa 3 de la epidemia, el virus está circulando por todo el país. Se considera que todos los pacientes están potencialmente infectados con SARS-CoV-2 y cualquier paciente sintomático (con tos y fiebre) se considera COVID-19 hasta que se demuestre lo contrario. Por lo tanto, en la fase 3 de la epidemia, se recomienda que los consultorios dentales de la ciudad apliquen las siguientes medidas:

1. Cierre de consultorios dentales a la recepción física de pacientes;

2. En la medida de lo posible, gestión remota de emergencias orales relativas (es decir, no requiere un acto terapéutico inmediato): teleconsulta, asesoramiento por correo electrónico.

3. Resolver emergencias orales que requieren un acto terapéutico.

\section{FASE 4}

En esta etapa el virus se dispersa en la comunidad: es casi imposible trazar un mapa de contagio y el número de casos se incrementan. Para evitar que la curva se acelere se restringe la movilidad en el país.

\section{FASE 5 Y 6}

Las últimas fases de la pandemia se dan cuando las medidas anteriores no han sido aplicadas con éxito y el número de casos salen de control. Se llega al pico más alto de la pandemia y las medidas siguen siendo extremas: se prohíbe la movilidad por completo de la población.

En el momento de la publicación en Uruguay estamos en la Fase 3 de la pandemia y por lo tanto este trabajo se va a situar en esa fase. 
Clasificación de riesgo del personal de salud: ${ }^{(5)}$

Rojo: riesgo alto frente al contagio por coronavirus: Clínicas dentales, Escuelas, Discotecas, Restoranes y bares, Peluquerías y estilistas, Gimnasios

Amarillo: riesgo medio frente al contagio por coronavirus

Verde: riesgo bajo frente al contagio por coronavirus

Los tipos de contagio son:

Persona a persona

Fómites persona

Hospedador portador sano (niños, portador asintomático)

El virus tiene afinidad por el receptor celular de la enzima convertidora de angiotensina 2 o ECA2, esto lleva al contagio persona a persona, porque el SARS-COV-2 invade estas células que abundan en tracto respiratorio, conductos salivales y el la boca en general.

ACE2 es un receptor importante para COVID-19. ${ }^{(6)}$

Las vías de contagio conocidas hasta el momento son:

Propagación por el aire

Inhalación porque el virus está en el aire

Contacto extendido

Contacto directo porque esta en sangre, fluidos, saliva, material que usamos con el paciente, conjuntiva, mucosa nasal, oral, aerosoles, gotas de Flügge.

Contacto con superficies contaminadas. ${ }^{(6)}$

Triage(fr), triaje o cribado para fase 3

El triage es un sistema de selección y clasificación de pacientes en los servicios de urgencia, basado en sus necesidades terapéuticas y los recursos disponibles para distinguir rápidamente a los pacientes que necesitan atención inmediata o diferenciada de aquellos que pueden esperar con seguridad la evaluación y el tratamiento. En el contexto actual, se prioriza la rápida identificación de caso sospechoso e implementación de medidas que disminuyan la diseminación de SARS-CoV27.

Existen distintos enfoques a) el de los signos vitales nulos b) la herramienta de detección en triage Identificar, Aislar e Informar. 
- Los signos vitales nulos hacen referencia a la necesidad de realizar una rápida detección de situaciones de riesgo epidémico antes de pasar a la toma de los signos vitales en el triage.

- La "herramienta de detección en triage: Identificar - Aislar - Informar" aporta una mirada rápida en relación a la forma de manejar desde el triage estos casos. Se propone esta última como la herramienta de detección para infección por virus SARS-CoV-2 en los Servicios de Urgencias Hospitalarios8.

Se recomienda en todos los casos realizar el triage previo a la consulta odontológica. ${ }^{(7)}$

Debe realizarse por vía telefónica previo a la asistencia del paciente al consultorio toda vez que sea posible con el propósito de identificar personas potencialmente sospechosas de presentar COVID-19.

Si no puede efectuarse vía telefónica, debe hacerse antes de decidir la atención del paciente al momento de su llegada al centro.

Procedimientos en la consulta odontólogica durante la pandemia

I) Cuestionario (5)

1- ¿Tiene o ha tenido fiebre (temperatura superior a $37.3^{\circ} \mathrm{C}-37.5^{\circ} \mathrm{C}$ ) en los últimos 14 días?

2- ¿Tiene o ha tenido problemas respiratorios en los últimos 14 días?

3- ¿Tiene o ha tenido malestar digestivo o sensación de mucho cansancio en los últimos 14 días?

4- ¿estuvo en contacto con personas con covid confirmado en los últimos 14 días?

5- ¿ha notado pérdida del gusto o del olfato en los últimos 14 días?

6- ¿ha pasado la enfermedad COVID 19? Sí si, ¿sigue en cuarentena?

II) Determinación y evaluación de la temperatura corporal.

Si el paciente dijo sí a alguna de las preguntas y la temperatura es inferior a $37.3^{\circ} \mathrm{C}$ puede diferirse el tratamiento hasta 14 días luego de la exposición supuesta.

Si dijo si y la temperatura es igual o mayor va a cuarentena y se notifica la infección sin asistencia

Si respondió no a todas y la temperatura es menor a $37.3^{\circ} \mathrm{C}$ el dentista puede tratar al paciente con medidas de protección evitando aerosoles.

Si respondió no pero la temperatura no es menor a $37.3^{\circ} \mathrm{C}$ no lo atiende y lo deriva a tratamiento médico, 
1. Paciente sospechoso de infección por coronavirus en el TRIAGE.

Suspender o postergar o no realizar el tratamiento, y proceder de acuerdo a las recomendaciones del Ministerio de Salud.

2. Paciente asintomático en el TRIAGE, se lo tratará con las medidas indicadas de cuidado para proceder a su atención.

III) Medidas generales para la asistencia

Reforzar el cumplimiento de las medidas universales para prevenir la transmisión de virus respiratorios, especialmente lavado de manos entre paciente y paciente. Espaciar los turnos odontológicos para evitar la acumulación de personas en las salas de espera.

No utilizar el ambo, ropa de trabajo, fuera del consultorio odontológico.

a) en la sala de espera:

Ventilar los ambientes de trabajo.

No usar aire acondicionado

No tener folletos y revistas.

b) recepción del paciente

Diferenciar horarios entre niños y adultos, evitar aglomeraciones.

Línea de recepción con mampara de metacrilato

Recepcionista debe llevar mascarilla quirúrgica y lentes.

Debe ofrecer gel hidroalcohólico

c) Indicaciones al paciente

Debe ser instruido previo a la visita.

En lo posible evitar que el paciente concurra acompañado.

SIn pulseras, collares, u otros accesorios.

Lavarse las manos o usar gel antiséptico hidroalcohólico.

Mantener distancia de 1 o 2 metros con otras personas.

Tratamientos en la Fase 3 de la Pandemia.

IV) Atención de urgencias en el consultorio odontológico

Atención y procedimientos de urgencia (Urgencia dental inaplazable: Infamación severa, sangrado postquirúrgico o postraumático, traumatismo dental severo o presencia de dolor dental intenso) se realizan en un consultorio acondicionado de manera que permita contar con todos los insumos para procedimientos generadores de aerosoles (PGA).

Los elementos de protección personal (EPP) son indispensables para proteger al profesional de la salud de infecciones, proteger a los pacientes de infectarse o prevenir que infecten a otros, dentro del marco del uso racional de los mismos. El incumplimiento de las medidas de prevención tiene una gran capacidad de amplificar la cadena de transmisión. 
El profesional, así como el resto de su equipo asistencial, debe estar protegido con las medidas de bioseguridad correspondientes al nivel de complejidad del caso:

Camisolín y cubre zapatos descartables e impermeables.

Cofia.

Gafas de protección ocular.

Pantalla facial protectora.

Guantes de látex.

Barbijo N95.

Intentar que durante la atención sólo estén el odontólogo y paciente en el consultorio, sin acompañantes (excepto que se trate de un paciente que así lo requiera por edad o patología previa)

El paciente debe lavarse las manos con jabón al entrar, secarse con papel y aplicarse alcohol en gel (gel hidroalcohólico $60 \%$ o superior) durante 20 segundos o alcohol etílico $70 \%$.

Indicar al paciente, antes de la atención, un colutorio con peróxido de hidrogeno al $1 \%$ o povidona iodada al $0.2 \%$ durante 30 segundos, escupir sin enjuagar, lo ideal sería la aspiración con el suctor. Otros compuestos como derivados de amonio cuaternario se mencionan en la literatura consultada. Si es indispensable el uso de instrumental rotatorio hacerlo bajo aislación absoluta y aspiración de alta potencia, esto reduce un $70 \%$ la producción de aerosoles.

Tener sobre la mesa de trabajo todo el material para la atención, guardando todo el resto, de tal manera que no sea necesario abrir cajones o tocar otras superficies.

Una vez finalizada la asistencia

-Descontaminar todas las superficies del consultorio, sala de espera y áreas comunes de los ambientes (sillas, pasamanos, manijas, puertas) con soluciones a base de alcohol (mínimo al $60 \%$ ) o hipoclorito de sodio o peróxido de hidrógeno al 3\% (agua oxigenada 10V).

-Ventilar ambiente.

-Eliminar en la bolsa roja el material descartable usado por el profesional y el paciente.

-Lavarse las manos con jabón antes de salir del consultorio.

-Lavarse todas las partes del cuerpo que hayan sido expuestas: cuello y pabellón auricular.

-Recordar que el uso de guantes no reemplaza el lavado de manos. La transmisión a través de las manos, por transmisión de contacto ha sido demostrada. La contaminación de la mano con virus y su posterior inoculación en mucosa oral, nasal u ocular es una importante vía de transmisión. El lavado de manos con agua y jabón es lo más efectivo en cuanto a medidas de prevención. Si las manos no están visiblemente sucias, puede emplearse 
solución de gel alcohólico. El uso del campo de látex permite reducir hasta en un $70 \%$ la producción de aerosoles generados por los procedimientos dentales.

Durante la Fase 3 de la pandemia se recomienda la realización de urgencias inaplazables solamente.

Fig. 1 Categorías de urgencias dentales y algoritmo de decisión

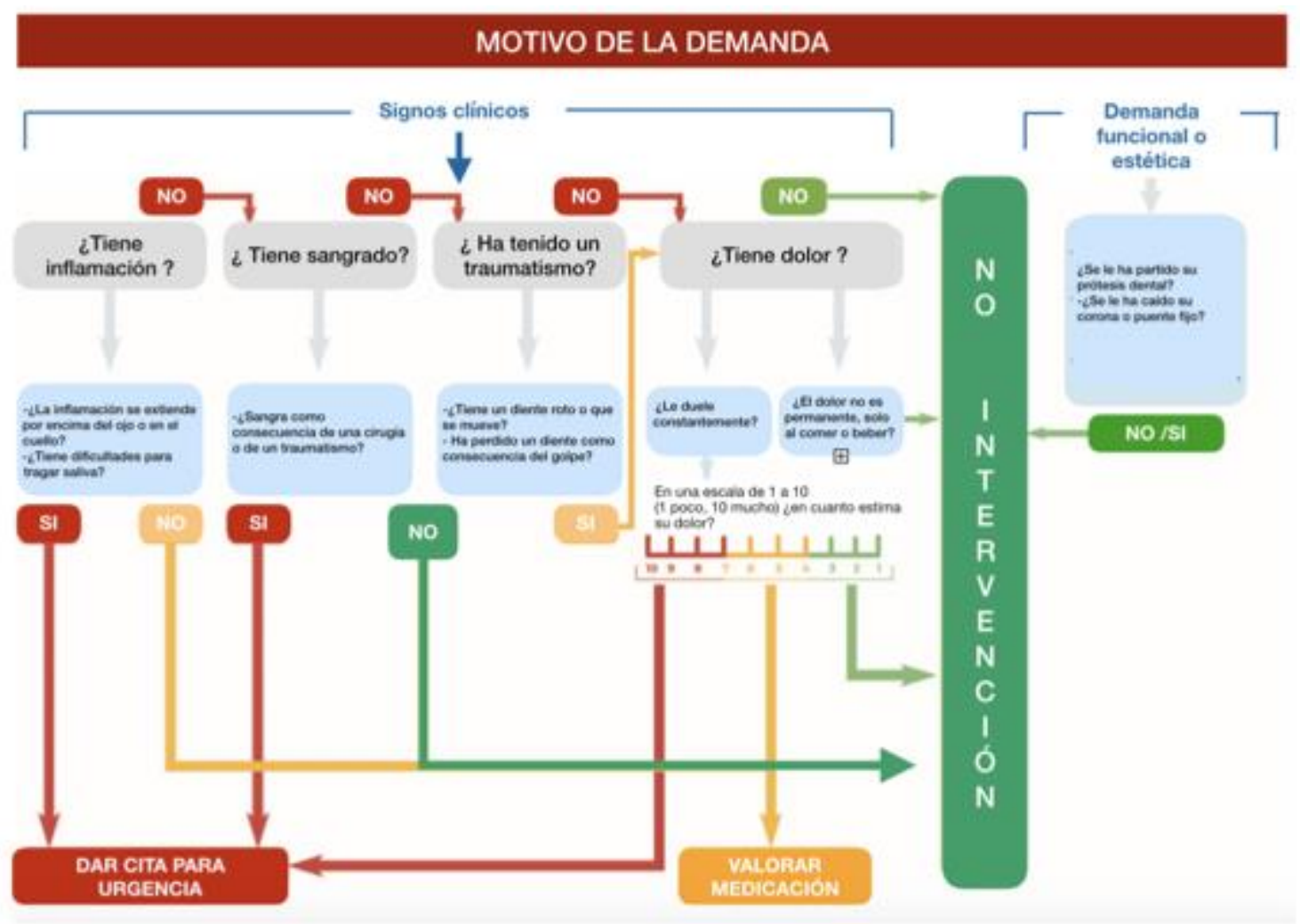

Tomado de Plan estratégico español (5)

Agentes antisépticos

Los estudios muestran que el virus puede sobrevivir de 2 a 8 horas en aluminio o superficies metálicas, vidrio 4 días, papel de 4 a 5 días, plástico hasta 5 días, madera 2 días, ropa 8 horas. ${ }^{(8)}$

Antisepsia de piel, (manos y campo externo): jabones, alcohol 70, peróxido de $\mathrm{H}$ $1 \%$, compuestos de amonio cuaternario, compuestos yodados. Si las manos no están visiblemente sucias puede emplearse solución de gel hidroalcohólico. ${ }^{(8)}$ Antisepsia de mucosas peróxido de hidrógeno, compuestos de amonio cuaternario, yodo polivinil pirrolidona. 
Tabla 1. Antisépticos, actividad virucida y seguridad del paciente

\begin{tabular}{|c|c|c|c|c|c|c|}
\hline $\begin{array}{c}\text { Agente } \\
\text { desinfectante }{ }^{\star *} \mathrm{O} \\
\text { antiséptico }\end{array}$ & $\begin{array}{l}\text { Presentación } \\
\text { Comercial }\end{array}$ & $\begin{array}{l}\text { Dilución } \\
\text { sugerida } \\
\text { para uso }\end{array}$ & Almacenamiento & Usos & Mecanismo de acción & Precauciones de seguridad \\
\hline $\begin{array}{l}\text { Alcohol etílico, } \\
\text { etanol } 70^{\circ}(\%)\end{array}$ & Bidón de 10 I & Sin diluir & Inflamable & $\begin{array}{l}\text { Antiséptico y } \\
\text { desinfectante. }\end{array}$ & $\begin{array}{l}\text { Desnaturaliza proteínas y reduce } \\
\text { tensión superficial }\end{array}$ & Inflamable. irritante. \\
\hline $\begin{array}{l}\text { Alcohol en gel } \\
\text { Etanol } 70^{\circ}(\%) \text { en el } \\
\text { hidroalcohólico }\end{array}$ & Envase $\times 250 \mathrm{ml}$ & Sin diluir & Ver fecha vencimiento & $\begin{array}{l}\text { Antiséptico y } \\
\text { desinfectante }\end{array}$ & & inflamable \\
\hline $\begin{array}{l}\text { Agua oxigenada, } \\
\text { peróxido de } \\
\text { hidrógeno } 10 \vee(0 \\
3 \%)\end{array}$ & Botella 11 & $\begin{array}{l}\text { Al } 3 \%, 1,5 \% \\
\text { y } 1 \% \text { (diluir } \\
\text { en agua } \\
\text { destilada) }\end{array}$ & $\begin{array}{l}\text { Al abrigo de luz y } \\
\text { temperatura. Recipiente } \\
\text { opaco. }\end{array}$ & $\begin{array}{l}\text { Antiséptico piel y } \\
\text { mucosas }\end{array}$ & $\begin{array}{l}\text { Acción limpiadora* por liberación } \\
\text { de oxígeno naciente. La } \\
\text { formación de radicales libres } \\
\text { hidroxilos, que contribuyen a } \\
\text { desestabilizar las molé- culas } \\
\text { celulares. }\end{array}$ & $\begin{array}{l}\text { Oxidante, fotosensible y } \\
\text { termolábil. }\end{array}$ \\
\hline $\begin{array}{l}\text { Yodo polivinil } \\
\text { pirrolidona al } 1 \%\end{array}$ & Botella 11 & $1 \%$ y $0,2 \%$ & Ver fecha vencimiento & $\begin{array}{l}\text { Antiséptico piel y } \\
\text { mucosas }\end{array}$ & Actúa por liberación de yodo. & Hipersensibilidad. \\
\hline $\begin{array}{l}\text { Derivado Amonio } \\
\text { Cuaternario: } \\
\text { Cloruro de } \\
\text { Benzalconio }\end{array}$ & Aerosol & Sin diluir & Ver fecha vencimiento & Desinfectante & $\begin{array}{l}\text { Son agentes catiónicos y actúan } \\
\text { a nivel de la membrana celular } \\
\text { (agentes activos de superficie). } \\
\text { Las principales aplicaciones se } \\
\text { dan para la desinfección de ítems } \\
\text { no críticos y desinfección } \\
\text { ambiental doméstica. }\end{array}$ & $\begin{array}{l}\text { Inactivo en presencia de } \\
\text { materia orgánica }\end{array}$ \\
\hline $\begin{array}{lr}\text { Hipoclorito } & \text { de } \\
\text { sodio } 10 \% & \\
\text { Hipoclorito } & \text { de } \\
\text { sodio } & \text { uso } \\
\text { doméstico } 4 \% & \end{array}$ & Bidón $10 \mathrm{I}$ & $\begin{array}{l}5 \%, \quad 4 \%, \\
2,5 \% . \\
\text { Superficies } \\
1000 \text { ppm } \\
\text { Calzado } \\
10000 \text { ppm }\end{array}$ & $\begin{array}{l}\text { Al abrigo de luz } \\
\text { y } \quad \text { temperatura. } \\
\text { Recipiente opaco. } \\
\text { Corrosivo. }\end{array}$ & Desinfectante & $\begin{array}{l}\text { Son agentes catiónicos y actúan } \\
\text { a nivel de la membrana celular } \\
\text { (agentes activos de superficie). } \\
\text { Las principales aplicaciones se } \\
\text { dan para la desinfección de ítems } \\
\text { no críticos y desinfección } \\
\text { ambiental doméstica. }\end{array}$ & $\begin{array}{l}\text { Cáustico, irritante, corrosivo. } \\
\text { reacciona violentamente con } \\
\text { múltiples sustancias } \\
\text { químicas }\end{array}$ \\
\hline $\begin{array}{l}\text { Hipoclorito } \\
\text { medicinal } 2,5 \% \text { y } \\
5 \%\end{array}$ & Frasco $\times 500 \mathrm{ml}$ & $\begin{array}{l}\text { Sin diluir } \\
\text { según } \\
\text { indicación }\end{array}$ & $\begin{array}{l}\text { Al abrigo de luz y } \\
\text { temperatura. Recipiente } \\
\text { opaco. } \\
\text { Corrosivo. }\end{array}$ & $\begin{array}{l}\text { Antiséptico y } \\
\text { desinfectante }\end{array}$ & & Cáustico, irritante, corrosivo. \\
\hline $\begin{array}{l}\text { Derivado Amonio } \\
\text { Cuaternario: } \\
\text { Cloruro de cetil } \\
\text { piridinio }\end{array}$ & $\begin{array}{l}0,05 \% \text { Fco } \times 250 \\
\text { ml } \\
\text { Presentación } \\
\text { comercial } \\
\text { contiene } \\
\text { Contiene } 0,05 \% \\
\text { de cloruro de } \\
\text { cetilpiridinio y } \\
1,5 \% \text { peróxido } \\
\text { de hidrógeno }\end{array}$ & Sin diluir & Ver fecha vencimiento & Antiséptico & & $\begin{array}{l}\text { Blanqueante, cosmético, } \\
\text { puede ser irritante de } \\
\text { mucosas. }\end{array}$ \\
\hline
\end{tabular}

* Limpiar significa eliminar la suciedad e impurezas, incluidos los gérmenes, de las superficies. La limpieza por sí sola no mata los gérmenes. Pero al eliminar los gérmenes, su cantidad disminuye al igual que el riesgo de propagar infecciones. ${ }^{(10)}$

**Desinfectar significa usar productos químicos, como desinfectantes registrados por la EPA, para matar los gérmenes de las superficies. Este proceso no limpia necesariamente las superficies sucias ni quita los gérmenes. Pero matar los gérmenes que quedan en la superficie luego de limpiar ayuda a reducir aún más el riesgo de propagación de infecciones. ${ }^{(10)}$ 
Tratamientos farmacológicos que puede recibir el paciente para COVID-19

Actualmente para los pacientes que requieren internación, más allá de las medidas de soporte, no se cuenta con evidencia robusta para administrar un un tratamiento farmacológico específico para el coronavirus SARS-CoV-2 Sin embargo se han prescripto terapias de uso compasivo y fuera de rótulo ("off label") fundamentadas en las propiedades antivirales o antiinflamatorias in vitro de varios medicamentos. En la mayoría de los casos se administraron sin considerar un grupo control, aunque se han realizado algunos ensayos aleatorios iniciados en China y en Estados Unidos.

Hasta el momento no hay evidencia clínica suficiente que respalde la eficacia y seguridad de ningún medicamento contra el SARS- CoV-2 en humanos.

Hoy en día, la tasa de curación de cuadros leves de Covid-19 puede alcanzar más de $90 \%$. Si un fármaco de prueba puede mejorar la efectividad al $95 \%$, cada ensayo clínico requeriría casi de 1000 participantes. La tasa de mortalidad del paciente con cuadro grave diagnosticado precozmente es de 6\%. Para que un fármaco en el ensayo clínico pueda reducir la tasa de mortalidad en $50 \%$, teóricamente, cada ensayo debería incluir a 800 pacientes críticos.

Medicamentos incluidos en el protocolo del estudio "Solidarity" de la Organización Mundial de la Salud (OMS).

- La hidroxicloroquina y la cloroquina son medicamentos antipalúdicos con efectos inmunomoduladores que se usan para tratar afecciones autoinmunes (por ejemplo, lupus eritematoso sistémico, artritis reumatoide) . La cloroquina e hidroxicloroquina inhibirían la replicación del SARS-CoV- in vivo. Si bien existe evidencia preclínica no se cuenta hasta el momento con evidencia clínica que apoye la efectividad de la cloroquina en pacientes con SARS- CoV-2. ${ }^{(14)}$

- El remdesivir es un fármaco de administración intravenosa que está en investigación. Es un análogo nucleótídico con actividad antiviral de amplio espectro. Inhibe la ARN polimerasa dependiente de ARN, que es en un $96 \%$ idéntica entre MERS, SARS y COVID-19.

- Interferones. Son citoquinas con receptor de membrana específico con actividad antiviral, propiedades antiproliferativas y efecto inmunomodulador. Hasta el momento, no existe evidencia suficiente para el uso de interferones en la enfermedad ocasionada por SARS-CoV-2.

- Lopinavir / ritonavir es una asociación de agentes antivirales utilizados en el tratamiento del VIH. El lopinavir es el agente que inhibe eficazmente la 
actividad proteasa del coronavirus. El ritonavir aumenta la vida media de lopinavir.

- Tocilizumab en un anticuerpo monoclonal. Actúa antagonizando el receptor de IL-6. Está aprobado actualmentes para el tratamiento de enfermedades reumatológicas autoinmunes como la Artritis Reumatoide o la Artritis Idiopática Juvenil .

El síndrome hiper inflamatorio (secondary hemophagocytic lymphohistiocytosis) se ha descrito en las infecciones virales, en pacientes con Covid-19 grave se han observado altas concentraciones de citocinas lo que podría determinar falla multiorgánica asociada al síndrome. (14)

\section{Analgesia en la consulta odontológica}

Actualmente no hay evidencia científica de calidad que establezca un vínculo entre el ibuprofeno y el empeoramiento de COVID-19 (AEMPS, 2020; INFARMED, 2020; HPRA, 2020; EMA, 2020; PAHO, 2020; FDA, 2020). El paracetamol continúa siendo la primera opción para fiebre o dolor. No hay evidencia científica que impida el uso de ibuprofeno para el tratamiento de los síntomas de COVID-19. Se recomienda utilizarlo en la dosis efectiva más baja y durante el período más corto posible ${ }^{(17)}$.

\section{Referencias}

1- European Centre for Disease Prevention and Control. Technical report, Disinfection of environments in healthcare and non- healthcare settings potentially contaminated with SARS-CoV-2. ECDC : Stockholm; 2020

2- van Dorleman N,

BushmakerT,MorrisDH,HolbrookMG,GambleA,WilliamsonBN,et al. Aerosoland Surface Stability of SARS-CoV-2 as Compared with SARS-CoV-1. N Engl J Med 2020; 382:1564-1567. Disponible en: https://www.nejm.org/doi/pdf/10.1056/NEJMc2004973. Acceso: 5/5/2020

3- Anexo $X$ Vigilancia de la gripe en el transcurso de la pandemia fases 4, 5 y 6 de la OMS. Subcomité de vigilancia, junio 2006. https://www.mscbs.gob.es/ciudadanos/enfLesiones/enfTransmisibles/docs/anex oX Septiembre2006.pdf

4-Méndez M., Umaña G. Recomendaciones de saneamiento ambiental en prevención del Covid-19. Asociación Interamericana de Ingeniería Sanitaria. Disponible en: https://aidis.org.uy/1655-2/. Acceso: 5/5/2020 
5-Organización Colegial de Dentistas de España. Plan Estratégico De Acción Para El Periodo Posterior A La Crisis Creada Por El Covid-19, 2020. Disponible en: https://coem.org.es/media/news/pdf/planAccionPostCovid19.pdf Acceso: $5 / 5 / 2020$

6- Peng, X., Xu, X., Li, Y., Cheng L., Zhou X., Ren B. Transmission routes of 2019-nCoV and controls in dental practice. Int J Oral Sci 2020; 12(9). https://doi.org/10.1038/s41368-020-0075-9

7- Argentina. Ministerio de Salud. Covid-19, Recomendaciones para la implementación del triage. 2020. Disponible en:

http://www.msal.gob.ar/images/stories/bes/graficos/0000001849cnt-covid-

19 recomendaciones-implementacion-triage.pdf

Acceso: 5/5/2020

8- Argentina. Ministerio de Salud . COVID-19 Recomendaciones en Odontología. 2020.

Disponible

en:http://www.msal.gob.ar/images/stories/bes/graficos/0000001881cnt-COVID-

Recomendaciones en odontologia 3-4.pdf.

Acceso: $11 / 5 / 2020$

9- American Dental Association. What Constitutes a Dental Emergency. [Infografía]. Disponible en: https://success.ada.org/ /media/CPS/Files/Open\%20Files/ADA COVID19 Den tal Emergency DDS.pdf

Acceso: 5/5/2020

10-Consenso colombiano de atención, diagnóstico y manejo de la infección por SARS-COV-2/COVID-19 en establecimientos de atención de la salud. Recomendaciones basadas en consenso de expertos e informados en la evidencia. Infectio: Revista de la Asociación Colombiana de Infectología 2020; 24(3(S1)). Disponible en:

https://scp.com.co/wp-content/uploads/2020/04/853-2770-1-PB.pdf

Acceso: 5/5/2020

11- Farmanuario Uruguay 2018. 28ed. Montevideo, 2019.

12- Vignoli E. Esterilización desinfección y antisepsia Instituto de Higiene,. En: Temas de Bacteriología y Virología Médica. Montevideo: Instituto de Higiene, 2006.

Disponible

en:

http://www.higiene.edu.uy/cefa/2008/esterilizacionydesinfeccion.pdf

Acceso: 5/5/2020

13- Colombia. Instituto de Hidrología, Meteorología y Estudios Ambientales.

Hipoclorito de sodio. Disponible en:

http://documentacion.ideam.gov.co/openbiblio/bvirtual/018903/Links/Guia18.pdf

Acceso: 5/5/2020 
14- Red de Centros de Información de Medicamentos de Latinoamérica y del Caribe. Tratamiento farmacológico para COVID-19: ¿cuál es la evidencia existente? 3 de abril de 2020 . Disponible en:

http://web2.redcimlac.org/index.php?option=com content\&view=article\&id=254

0 :tratamiento-farmacologico-para-covid-19-icual-es-la-evidencia-

existente\&catid $=4$ : noticias-de-interes $\&$ Itemid $=31$

Acceso: $5 / 5 / 2020$

15- Red de Centros de Información de Medicamentos de Latinoamérica y del Caribe. ¿Qué se sabe sobre ibuprofeno y otros antiinflamatorios no esteroideos (AINE) en relación con COVID-19? 20 de marzo de 2020. Disponible en:

http://www.farmacologia.hc.edu.uy/images/documento ibuprofeno AINES Re dcimlac.pdf

Acceso: 5/5/2020 